\title{
Effects of Addition of Polyacrylic Ammonium on Colloidal Processing of $\alpha$-Alumina
}

\author{
Yoshihiro HIRATA, Akihiko NISHIMOTO and Yoshimi ISHIHARA \\ Department of Applied Chemistry and Chemical Engineering, Faculty of Engineering, Kagoshima University, \\ 1-21-40, Korimoto, Kagoshima-shi 890

\section{$\alpha$-アルミナのコロイドプロセッシングにおけるポリアクリル酸アンモニウムの添加効果 \\ 平田好洋・西本昭彦・石原義巳} \\ 鹿児島大学工学部応用化学工学科, 890 鹿児島市郡元 1-21-40
}

[Received January 12, 1992; Accepted April 23, 1992]

\begin{abstract}
Effects of addition of polyacrylic ammonium (shorten as PAN) on the rheological properties of aqueous alumina suspensions, pore size distributions and sintering behavior of consolidated powder compacts were studied to reduce fluctuation of microstructure and density in powder processing. It was possible to prepare a highly concentrated fluid alumina suspension of $\sim \mathbf{6 3}$ vol\% solids by controlling the electrosteric stabilization effect of negatively charged polymer which was adsorbed onto alumina surface. Combustion of adsorbed polymer at $1000^{\circ} \mathrm{C}$ formed continuous narrow pore size distributions in the alumina compacts with 60.2 to $67.2 \%$ T.D., depending on solids content of suspensions. The densification of high-density alumina compacts proceeded at low sintering temperatures through disappearance of closed pores which were formed at around $92-95 \%$ T. D. The low-density compacts were densified at high temperatures without significant formation of closed pores. The texture of sintered alumina was strongly affected by the pore size distribution of the starting alumina compact, which greatly depended on the consolidation processes of powder (i.e., filtration or doctor blade method) and the electrosteric effect of added polymer in suspension stage. Addition of PAN was effective in achieving a fine microstructure of narrow grain size distribution.
\end{abstract}

Key-words : Polyacrylic ammonium, Colloidal processing, Alumina, Electrosteric stabilization, Rheology, Pore size distribution, Sintering

\section{Introduction}

Function of advanced ceramics used in electronic, magnetic, optical, or high temperature structural materials application, depends greatly upon their microstructures. Recent progress in materials development has accelerated nanometer size-control of texture. ${ }^{1), 2)}$ On the other hand, reliable processing and microstructure control have to be established for submicrometer size powders used in many industrial applications. We have reported usefulness of colloidal processing with powder suspensions in controlling fluctuation of green density and green structure. ${ }^{3)-10)}$ The achievement of uniform green structure is effective to increase physicochemical properties of advanced ceramics. For instance, the dense mullite ceramics prepared by filtration of an aqueous suspension showed the remarkably high flexural strengths of $425-468 \mathrm{MPa}$ at $25^{\circ}-$ $1300^{\circ} \mathrm{C}^{8)}{ }^{-10)}$ In collolidal processing, stability of powder suspensions has an important role on the properties of consolidated powder compacts. Electrosteric stabilization of suspension with organic or inorganic surfactant is a key process as well as electrostatic stabilization to make highly concentrated fluid suspensions.5),11),12) We also reported the interaction between alumina surface and polyacrylic acid (PAA).13) In this paper, following electrosteric effects of polyacrylic ammonium (shorten as PAN) were investigated: (i) the rheological properties of PAN-added alumina suspensions, (ii) the properties of alumina compacts formed by filtration through gypsum molds and doctor blade method, and (iii) the sintering behavior of green compacts.

\section{Experimental procedure}

A high purity $\alpha$-alumina powder of a specific surface area of $4.3 \mathrm{~m}^{2} / \mathrm{g}$ (purity $>99.99 \%$, diameter of equivalent spherical particle: $0.35 \mu \mathrm{m}$, Sumitomo Chemical Co., Ltd., Tokyo, Japan) and polyacrylic ammonium with an average molecular weight of $10000\left(-\left(\mathrm{HCCOONH}_{4} \mathrm{CH}_{2}\right)_{n}\right.$, Dai-ichi Kogyo Seiyaku Co., Ltd., Kyoto, Japan) were used in this experiment. The alumina powder consisted of equiaxised primary particles with a size distribution of 0.1 to $1.1 \mu \mathrm{m}$. Zeta potential of the alumina particles in dilute suspensions $(0.02 \mathrm{wt} \%)$ was measured at the $\mathrm{pH}$ range of 2.2 to 10.5 , where $0.01 \mathrm{~N} \mathrm{HCl}$ or $0.01 \mathrm{~N} \mathrm{NH}_{4} \mathrm{OH}$ solution was used for $\mathrm{pH}$ adjustment (Zeta-Meter Inc., U.S.A.). The alumina powder and PAN solution were mixed in water of $\mathrm{pH} 9.0$ at solids content of 20.8 to $62.3 \mathrm{vol} \%$. The electrostatically stabilized alumina suspensions were also prepared at $\mathrm{pH} 2.5$ by adding $\mathrm{HCl}$ solution at solids content of 13.0 to $52.1 \mathrm{vol} \%$. After the suspensions were stirred for $24 \mathrm{~h}$, ultrasonic vibration $(20 \mathrm{kHz})$ was applied for $5 \mathrm{~min}$ to facilitate the complete dis- 
persion of powder. Air bubbles in the suspensions were eliminated in a bell jar connected to a vacuum pump. Shear rate $(\dot{\gamma})$ versus shear stress $(S)$ relation of the suspensions was measured by a cone and plate viscometer at room temperature (Visconic EMD type, Tokyo Keiki Co., Tokyo, Japan). The alumina particles in the suspensions were consolidated by filtration through gypsum molds or doctor blade method (DP-100, Tsugawa Seiki Seisakusho, Tokyo, Japan). A blade clearance of doctor blade method was set to $1 \mathrm{~mm}$, and polyethylene carrier tape was transferred at a rate of $15 \mathrm{~cm} / \mathrm{min}$.

The alumina green compacts dried at $110^{\circ} \mathrm{C}$ were heated at $1000^{\circ} \mathrm{C}$ for $1 \mathrm{~h}$ to burn out the adsorbed PAN. The densities, microstructures, and pore size distributions of calcined alumina compacts were investigated by the Archimedes method using distilled water, a scanning electron microscopy (SEM; H7010A type, Hitachi, Ltd., Tokyo, Japan), and mercury porosimeter (Aminco 60000 psi Mercury-Intrusion Porosimeter, American Instrument Co., U.S.A.), respectively. The calcined alumina compacts were sintered at $1100^{\circ}$ to $1600^{\circ} \mathrm{C}$ for $1 \mathrm{~h}$. The heating rate was controlled to $10^{\circ} \mathrm{C} / \mathrm{min}$. The densities of sintered alumina were determined by the Archimedes method using distilled water. The sintered alumina was polished with $0.25 \mu \mathrm{m}$-diamond paste and thermally etched at $100^{\circ} \mathrm{C}$ lower than the sintering temperature for $1 \mathrm{~h}$ to observe the microstructure.

\section{Results and discussion}

3.1 Rheological properties of PAN-added suspensions

Figure 1 shows the zeta potential of alumina suspensions (A) and the critical amount of carboxyl group (B) where the added polymer (polyacrylic acid) was completely absorbed onto the alumina surface. ${ }^{13)}$ An isoelectric point of $\alpha$-alumina particles was about $\mathrm{pH} 7.7$, and the alumina surface was

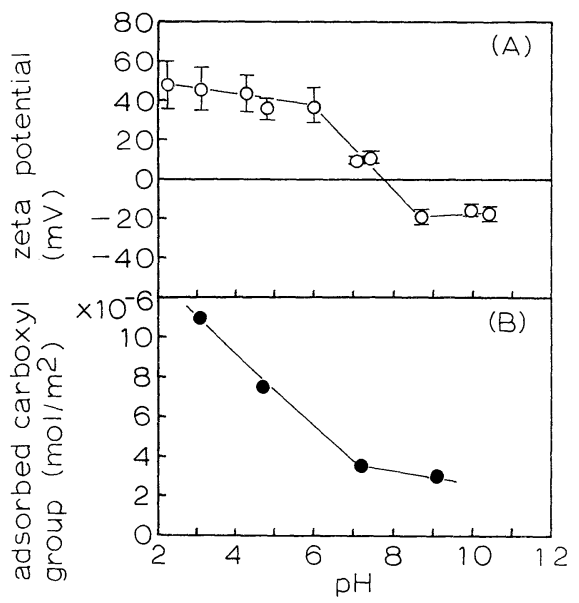

Fig. 1. Zeta potential of colloidal $\alpha-\mathrm{Al}_{2} \mathrm{O}_{3}$ particles (A) and critical amount of carboxyl group (B) where added polyacrylic acid was completely adsorbed onto alumina surface. ${ }^{13)}$ charged positively and negatively at $\mathrm{pH}$ below and above 7.7, respectively. As seen in Fig. 1, the critical amount of carboxyl group was lower at higher $\mathrm{pH}$ owing to the electrostatic repulsion between negatively charged polymer and negative sites of alumina surface. ${ }^{13)}$ Electrosteric and electrostatic stabilization of suspensions were investigated at $\mathrm{pH} 9.0$ and at $\mathrm{pH} 2.5$, resectively, because the necessary amount of PAN for stabilization of suspensions can be reduced at high $\mathrm{pH}$ and the highly charged alumina particles at $\mathrm{pH} 2.5$ are well dispersed due to the strong electrostatic repulsion force. ${ }^{14)}$

Figure 2 shows the effect of PAN-addition on the zeta potential of $\alpha$-alumina particles. The zeta potential at $\mathrm{pH} 9.0$ decreased from $-24 \mathrm{mV}$ for no addition of PAN to $-40 \mathrm{mV}$ for the addition of carboxyl group of 3.5 to $17.0 \times 10^{-6} \mathrm{~mol} / \mathrm{m}^{2}$. The decrease of zeta potential with addition of PAN is due to the adsorption of negatively charged polymer onto the alumina surface. ${ }^{11)}$ The maximum amount of adsorbed carboxyl group was determined to be $3.5 \times 10^{-6}$ $\mathrm{mol} / \mathrm{m}^{2}$ of alumina surface at $\mathrm{pH} 9.0$ in the previous experiment (Fig. 1).13) The equilibrium zeta potential with addition of a large amount of polymer supports that free PAN above the critical amount did not affect the zeta potential.

Figure 3 shows the typical rheological behavior

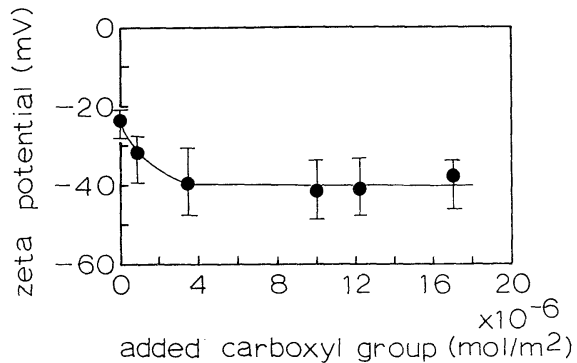

Fig. 2. Zeta potential of alumina particles in aqueous suspensions containing polyacrylic ammonium (PAN) at $\mathrm{pH} 9.0$.

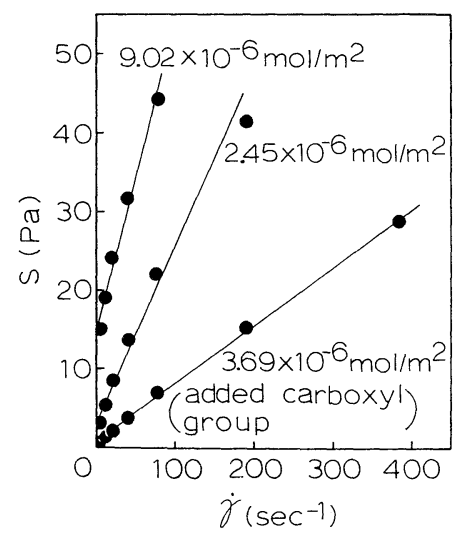

Fig. 3. Typical shear rate $(\dot{\gamma})$-shear stress $(S)$ relation for the PAN-added alumina suspensions of solids content of $52 \pm 3 \mathrm{vol} \%$ at $\mathrm{pH} 9.0$. 
for the PAN-added alumina suspensions of $52 \pm 3$ vol\% solids at $\mathrm{pH} 9.0$. The shear rate $(\dot{\gamma})$-shear stress $(S)$ relation was approximated to Bingham flow $\left(S=S_{0}+\eta \dot{\gamma}, S_{0}\right.$ : yield stress, $\eta$ : viscosity). In this paper, the rheological properties of alumina suspensions were evaluated by the values of $S_{0}$ and $\eta$.

Figure 4 shows the viscosities of alumina suspensions at $\mathrm{pH} 9.0$ as a function of amount of added carboxyl group. The viscosities showed first minima at the critical amount of PAN. Decrease of viscosity with addition of PAN below the critical amount would be explained by the increase of strong repulsive interaction between PAN-coated alumina particles (Fig. 2). Increase of viscosity with addition of PAN above the critical amount would be due to the electrosteric repulsion; (i) among negatively charged free polymer themselves and (ii) between free negative polymer and the negative polymer adsorbed on alumina surface. The effect of free polymer on viscosity was confirmed with aqueous PAN solutions at $\mathrm{pH} 9.0$. Figure 5 shows the viscosities of polymer solutions as a function of carboxyl group concentration, indicating the electrosteric repulsion among free negative polymer. Since it was found in the previous experiment that a small amount of the excess polymer above the critical amount was adsorbed onto alumina surface, ${ }^{13)}$ the free polymer concentration for 52 vol\% solids suspension in Fig. 5 was calculated in consideration of the additional adsorption of polymer. A good similarity of dependence of viscosity on free polymer content was ob- served between the PAN solutions and PAN-added alumina suspensions. The difference in magnitude of viscosity between the suspension and PAN solution can be explained by the effect of solid particles. Addition of alumina particles leads to the interaction among negatively coated particles in addition to free polymer interaction. As seen in Figs. 4 or 5 , more addition of PAN caused second minima of viscosity as a function of polymer content. Polymer content dependence of $S_{0}$ value was also similar to that of $\eta$ value shown in Fig. 4. The second minima of viscosity may be associated with the configuration change of polymer with increasing concentration of $\mathrm{NH}_{4}{ }^{+}$counter ion of negative polymer. High concentration of counter ion may reduce the electrosteric repulsion among negatively charged polymer. As a result, the linear polymer may change its configuration, resulting in decrease of effective interaction space. The increase of viscosity after the second minima seems to reflect the electrosteric repulsion of polymer with different configuration compared with dilute polymer solutions.

Figures 6 and 7 show solids content dependence of viscosity and yield stress, respectively, for the electrosterically stabilized alumina suspensions with the critical amount of carboxyl group at $\mathrm{pH} 9.0$ and the electrostatically stabilized alumina suspensions at $\mathrm{pH}$ 2.5. Both the suspensions showed similar viscosities as a function of solids content (Fig. 6), while yield stress was lower for the PAN-added suspensions than the alumina suspensions without PAN. In

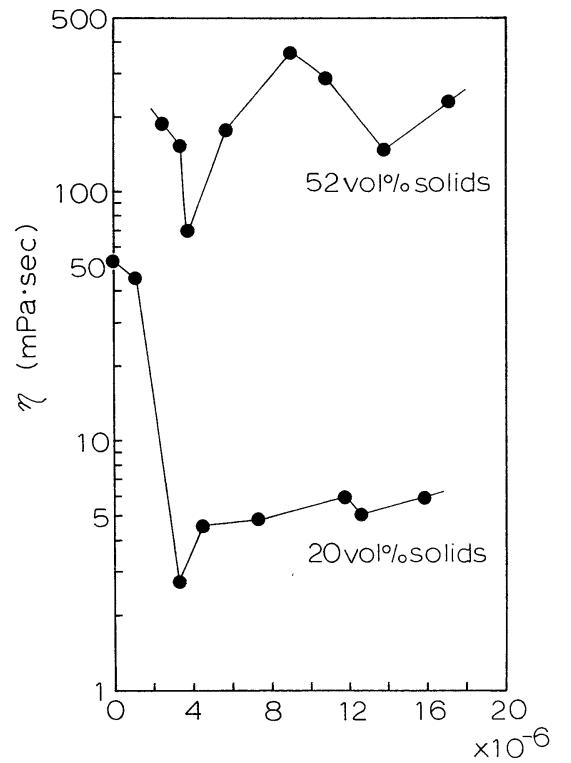

added carboxyl group $\left(\mathrm{mol} / \mathrm{m}^{2}\right)$

Fig. 4

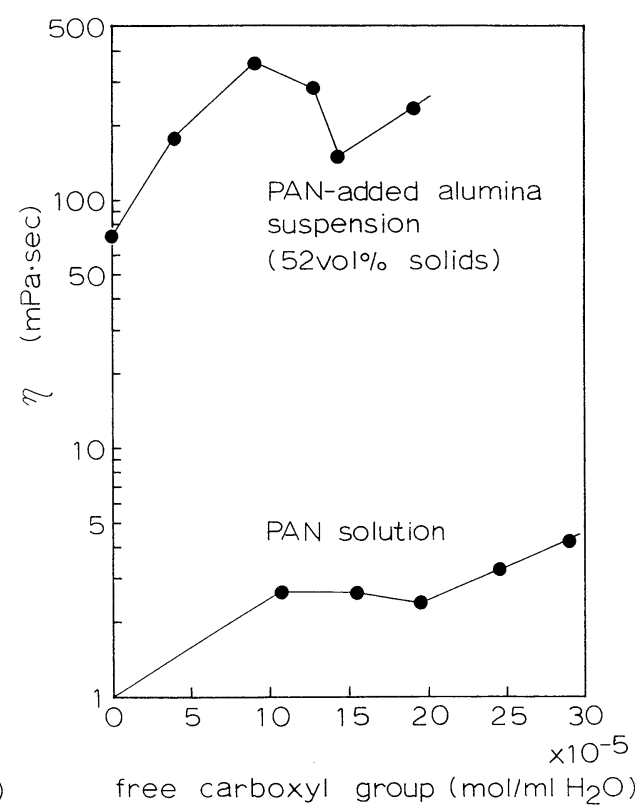

Fig. 5

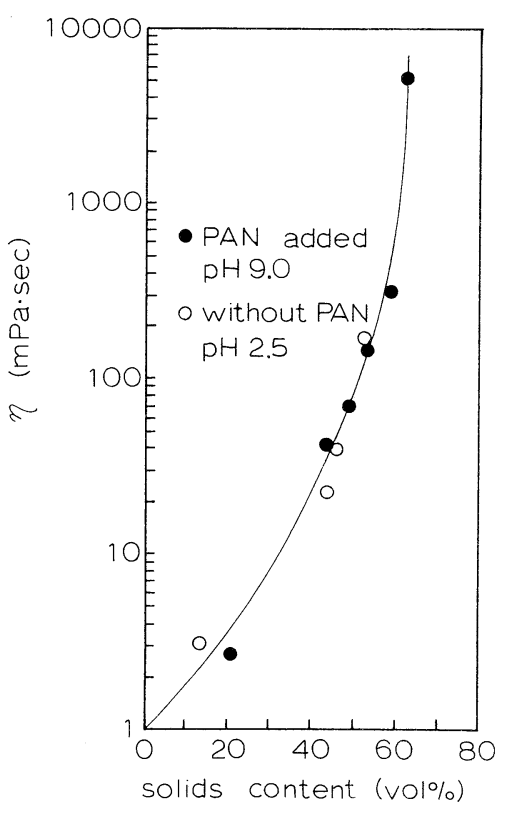

Fig. 6

Fig. 4. Viscosities of alumina suspensions with solids content of 20 and 52 vol\% at pH 9.0 as a function of amount of added carboxyl group per $\mathrm{m}^{2}$ of alumina surface.

Fig. 5. Viscosities of PAN solutions and PAN-added alumina suspensions with excess free polymer above a critical amount at $\mathrm{pH} 9.0$.

Fig. 6. Solids content dependence of viscosity for electrosterically stabilized alumina suspensions with carboxyl group of $3.5 \times 10^{-6} \mathrm{~mol} /$ $\mathrm{m}^{2}$ at $\mathrm{pH} 9.0$ and for electrostatically stabilized alumina suspensions at $\mathrm{pH} 2.5$. 


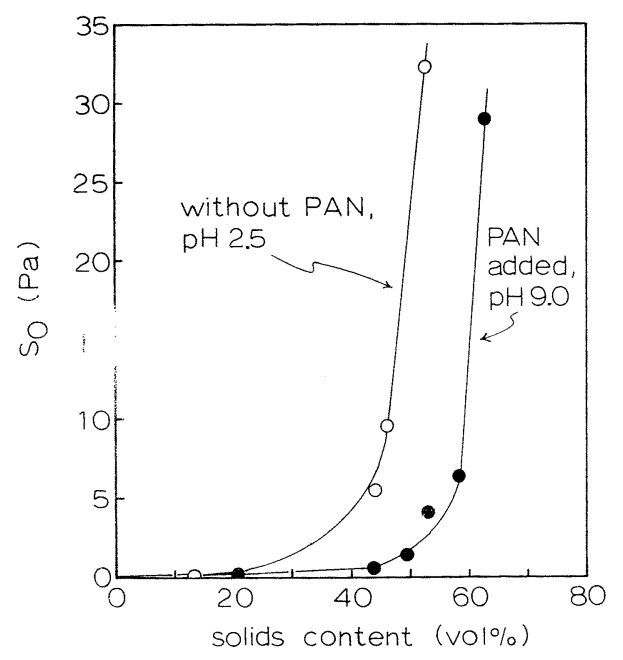

Fig. 7. Solids content dependence of yield stress for electrosterically stabilized alumina suspensions with carboxyl group of $3.5 \times$ $10^{-6} \mathrm{~mol} / \mathrm{m}^{2}$ at $\mathrm{pH} 9.0$ and for electrostatically stabilized alumina suspensions at $\mathrm{pH} 2.5$.

this experiment, it was difficult to increase the solids content of fluid suspensions above 53 vol\% by electrostatic stabilization and above $63 \mathrm{vol} \%$ by electrosteric stabilization. These results indicate that electrosteric stabilization is superior to electrostatic stabilization to prepare highly concentrated fluid suspensions.

The effect of PAN-addition on the increase of solids concentration is interpreted by an interaction energy curve (summation of two curves of van der Waals' attraction energy and repulsive energy by

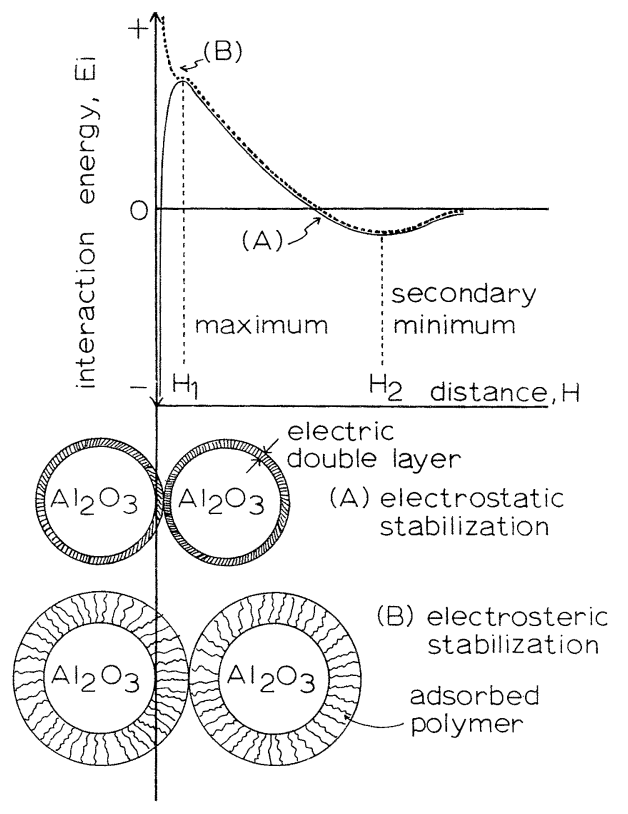

Fig. 8. A schematic illustration explaining interaction of alumina particles for electrostatic and electrosteric stabilization. Particles without polymer form clusters when they approach each other at the distance shorter than $H_{1}$. Adsorbed polymer prevents the formation of particle clusters. electric double layer) as a function of particle distance. ${ }^{14)}$ As shown in schematical Fig. 8(A), the interaction curve shows a maximum at the particle distance $H_{1}$ shorter than $\approx 20 \mathrm{~nm}$, depending on the particle charge. ${ }^{14)}$ Particles form clusters when they approach each other at the distance shorter than $H_{1}$. The increase of solids content of suspensions indicates the decrease of average particle distance, accelerating the formation of network structure of particle clusters. The alumina particles coated by PAN can not approach a certain minimum particle distance, depending on the thickness of PAN layer (Fig. 8(B)). In addition, electrosteric stabilization increases the positive interaction energy when polymer-coated particles encounter. ${ }^{15), 16)}$ That is, PANcoating of alumina particles prevents the formation of particle clusters because of no primary minimum of interaction energy curve. This mechanism leads to the increase of solids content of fluid suspensions.

\subsection{Consolidation of PAN-added alumina sus-} pensions

The alumina suspensions electrosterically stabilized by PAN $\left(3.5 \times 10^{-6} \mathrm{~mol}\right.$ of carboxyl group $\left./ \mathrm{m}^{2}\right)$ were consolidated by filtration through gypsum molds and by doctor blade. Figure 9 shows the relative densities of alumina compacts after combustion of adsorbed PAN at $1000^{\circ} \mathrm{C}$ for $1 \mathrm{~h}$. In Fig. 9, the data by filtration for the electrostatically stabilized alumina suspensions at $\mathrm{pH} 2.5$ were also shown to compare with the data for electrosteric stabilization. The result in electrostatic stabilization indicates clearly that the alumina particles dispersed randomly in suspension stage were consolidated to an ordered polycrystalline-like structure during filtration. ${ }^{17)}$ Although the maximum packing density of monosize spherical particles is well known to be $74 \%$ in H.C.P. (Hexagonal Close-packing) or F.C.C. (Face-centered Cubic Close-packing) structure, it is difficult to achieve this theoretical density in actual

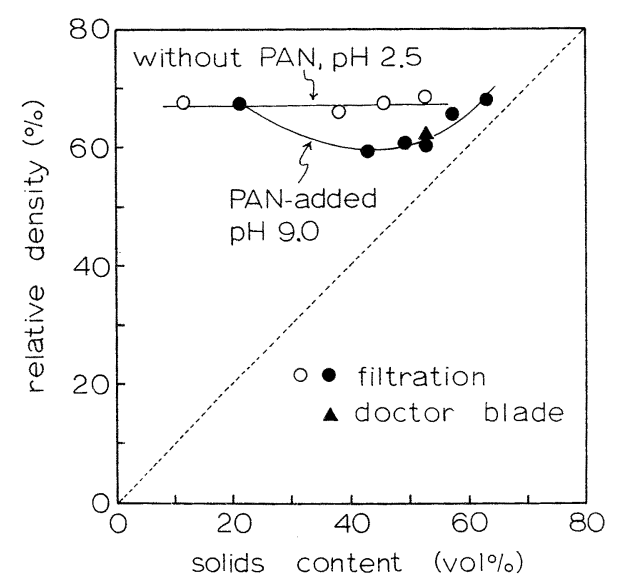

Fig. 9. Relative densities of alumina compacts calcined at $1000^{\circ} \mathrm{C}$ for $1 \mathrm{~h}$ as a function of solids content of electrostatically stabilized suspensions at $\mathrm{pH} 2.5$ and electrosterically stabilized suspensions with carboxyl group of $3.5 \times 10^{-6} \mathrm{~mol} / \mathrm{m}^{2}$ at $\mathrm{pH} 9.0$. 
powder processing because of a finite particle size distribution. The consolidation phenomenon in Fig. 9 is similar to the phase transformation from liquid to crystalline solids in atomic systems. ${ }^{17)}$

On the other hand, the green density for electrosteric stabilization showed a minimum at around 40 vol\% solids content. The slope of green density curve was close to 1 above 40 vol\% solids content. The straight line with a slope 1 passing the origin of Fig. 9 corresponds to the consolidation by freezedrying of a suspension stage, indicating no crystallization of disordered-structure particles during consolidation. In other words, the consolidation expressed by the straight line passing the origin resembles the glass formation from liquid phase in atomic systems. The powder consolidation from the electrosterically stabilized suspensions with high solids content resembles the formation of partially crystallized glass. Decrease of distance between two polymer-coated particles with increasing solids content causes strong positive electrosteric repulsion (Fig. $8(B))$. This may disturb the ordering of alumina particles during consolidation in addition to preventing the direct contact between alumina particles. As seen in Fig. 9, the PAN-added suspension with 20 vol\% solids formed a high density green compact. This result is close to that for electrostatic stabilization and may suggest that weak electrosteric repulsion between adsorbed polymer with decreasing solids content does not affect the ordering of particles during consolidation.

\subsection{Pore structures of green compacts}

Figure 10 shows the pore size distributions of alumina compacts which were heated at $1000^{\circ} \mathrm{C}$ to burn out the adsorbed PAN. In the alumina compacts with

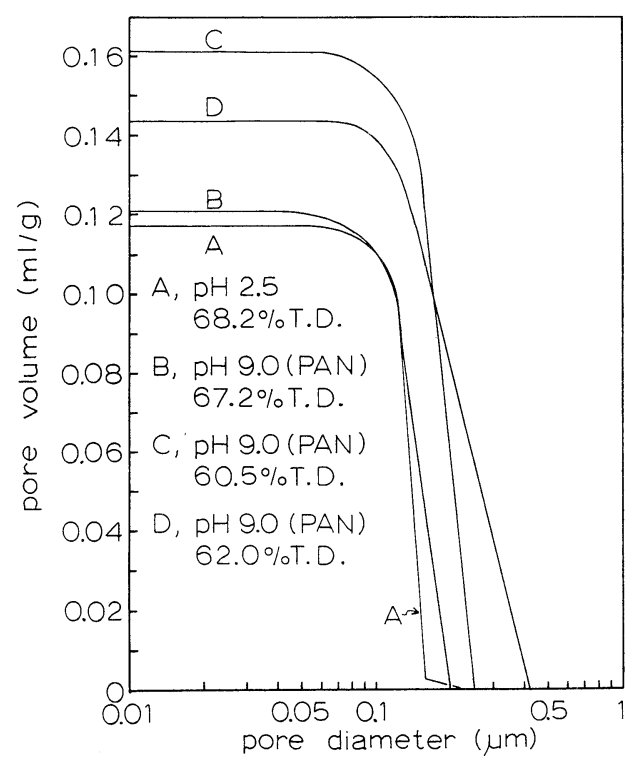

Fig. 10. Cumulative pore volume of alumina compacts calcined at $1000^{\circ} \mathrm{C}$ for $1 \mathrm{~h}$, which were formed by filtration (A, B and $\mathrm{C}$ ) and doctor blade method (D). Percent in Fig. 10 indicates the relative density of alumina compact. relative densities of 60.5 to $68.2 \%$, pores of diameters in the range of 0.08 to $0.42 \mu$ m were formed. The median sizes of pore were $0.13 \mu \mathrm{m}$ for the $68.2 \%$ T. D. compact (A) consolidated by filtration of an electrostatically stabilized suspension with solids content of $52.1 \mathrm{vol} \%, 0.15 \mu \mathrm{m}$ (B) and 0.19 $\mu \mathrm{m}(\mathrm{C})$ for the 67.2 and $60.5 \%$ T. D. compacts, consolidated by filtration of PAN-added suspensions with solids content of 62.3 and 52.6 vol\%, respective$1 \mathrm{y}$, and $0.22 \mu \mathrm{m}$ (D) for the $62.0 \% \mathrm{~T}$. D. compact formed by doctor blade of PAN-added suspension with solids content of $53.0 \mathrm{vol} \%$, indicating clearly that density increase leads to the decrease of average pore size. ${ }^{18)}$ It is noted that the diameters of spherical pores close-packed in the spaces of primary particles of F.C.C. structure are calculated to be 0.079 and $0.14 \mu \mathrm{m}$ for the 4- and 6-coordination pores, respectively $\left(D_{\mathrm{p}}=k D, D_{\mathrm{p}}\right.$ : pore diameter, $D$ : particle diameter $(0.35 \mu \mathrm{m}), k: 0.2247$ and 0.4142 for $4-$ and 6-coordination pores). 18) This calculation suggests that samples A and B contained more 1st-generation pores formed among primary particles than 2nd generation pores formed among 1st-generation clusters, but samples C and D contained more 2ndgeneration pores than 1 st generation pores. ${ }^{18)}$ The diameter of spherical clusters corresponding to the maximum pores of $0.42 \mu \mathrm{m}$-diameter (6-coordination pores) in sample $\mathrm{D}$ was estimated to be $1.0 \mu \mathrm{m}$.

As shown in Fig. 10, filtration process gave a narrower pore size distribution than doctor blade method at the similar compact densities (samples C and $\mathrm{D})$. In filtration process, the alumina particles coated by PAN in the suspension were consolidated with partial ordering during absorption of liquid media through gypsum mold (see Section 3.2). On the other hand, the particles in the concentrated suspension layer rapidly formed by doctor blade on polyethylene carrier film were consolidated by short-distance sedimentation due to particle gravity and evaporation of water during drying. This process seems to inherit more the disordered particle structure in the suspension stage than filtration. That is, the wide pore size distribution for doctor blade method would reflect less change in particle conformation during consolidation. Sample A contained a small amount of pores reaching $0.2 \mu \mathrm{m}$. Compared with sample A, sample B showed a more continuous pore size distribution within $0.2 \mu \mathrm{m}$ at the similar densities. ${ }^{3)}$ These results would be explained by the effect of PAN-addition on the ordering of particles during consolidation, as discussed in Section 3.2.

Figure 11 shows the microstructures of samples A, B, C, and D. A comparison of the SEM photographs suggests that particles in the PAN-added suspensions (samples B, C, and D) were consolidated in more uniform structures than those in the suspension without PAN (sample A).5) These uniform structures are reflected in the continuous pore size distributions in Fig. 10. On the other hand, the alumi- 


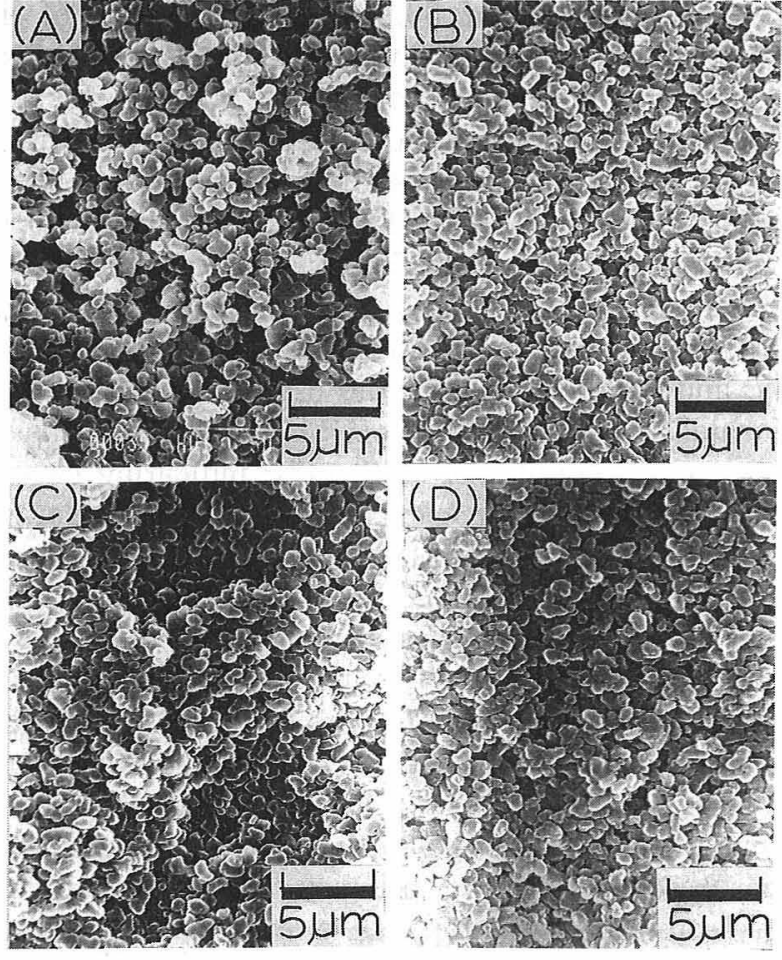

Fig. 11. Microstructures of alumina compacts calcined at $1000^{\circ} \mathrm{C}$ for $1 \mathrm{~h}$. Samples are same as Fig. 10.

na particles in the suspension without PAN (sample A) were aggregated to dense clusters during filtration and these clusters formed high hierarchical pores. These pores in sample $A$ are reflected in the pore size distribution in Fig. 10.

\subsection{Sintering behavior}

Figure 12 shows the sintering behavior of alumina compacts formed from electrosterically and electrostatically stabilized suspensions. The densification rates of alumina compacts were strongly dominated by the green density rather than the kinds of consolidation processes. However, the consolidation process (filtration or doctor blade method) affected greatly the sintered microstructures of alumina, as

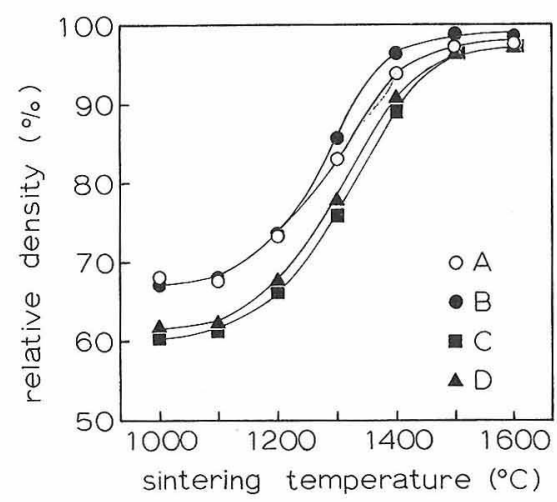

Fig. 12. Sintering behavior of alumina compacts formed by filtration and doctor blade method of electrostatically (A) and electrosterically stabilized suspensions (B, C and D). Samples are same as Fig. 10. mentioned later. Density difference between samples $\mathrm{B}$ and $\mathrm{C}$ or $\mathrm{D}$ is related to the difference in pore size distributions of green compacts. As shown in Fig. 12, small pores of low coordination numbers can be easily eliminated at low sintering temperatures, giving a higher density at the final stage of sintering. In other words, high-degree grain growth is needed at high temperatures for low green density-compacts to eliminate large pores by reducing the coordination numbers of pores. Another interesting result is the density difference between samples A and B. PANaddition in suspension stage (sample B) was effective to achieve a higher density at the final stage of sintering. ${ }^{5)}$ This reason may be related to the uniform structure in sample B (Fig. 11) because sample A contained a small amount of relatively large pores which reduce the densification rate at the final stage of sintering.

Figure 13 illustrates the comparison of porosities of closed pores for samples A, B, C, and D as a function of relative density. Densification of low densitygreen compacts (samples C and D) proceeded without the significant formation of closed pores. In high density-green compacts (samples $\mathrm{A}$ and $\mathrm{B}$ ), densification proceeded with disappearance of closed pores which were formed at 92-95\% T. D. These results indicate that large pores of high coordination numbers prevent the formation of closed pores.

Figure 14 shows the microstructures of samples $\mathrm{A}, \mathrm{B}, \mathrm{C}$, and $\mathrm{D}$ sintered at $1600^{\circ} \mathrm{C}$ for $1 \mathrm{~h}$. Grain size distributions were in the range of $0.3-8.1 \mu \mathrm{m}$ (average $3.6 \mu \mathrm{m})$ for sample A $(97.7 \%$ T. D.), $0.3-$ $5.8 \mu \mathrm{m}$ (average $2.7 \mu \mathrm{m})$ for sample B $(98.5 \% \mathrm{~T}$. D.), $0.6-4.8 \mu \mathrm{m}$ (average $2.6 \mu \mathrm{m}$ ) for sample $\mathrm{C}$ (97.8\% T. D.) and 0.6-9.4 $\mu \mathrm{m}$ (average $4.0 \mu \mathrm{m}$ ) for sample D $(97.7 \%$ T. D.). The grain size distributions showed a good relation to the pore size distributions of green compacts (Fig. 10). Therefore, a continuous narrow pore size distribution gave a narrow grain size distribution. ${ }^{5)}$ The difference in micros-

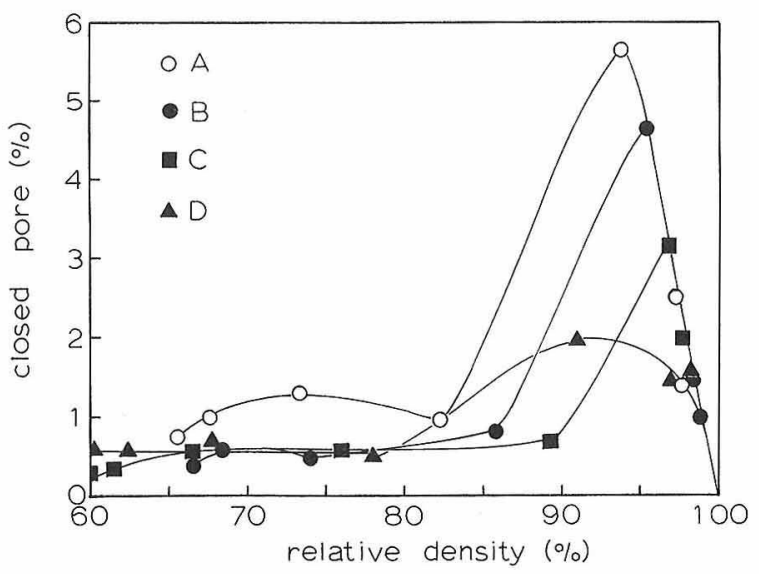

Fig. 13. Porosities of closed pores and relative densities of alumina compacts. Samples are same as Fig. 10. 

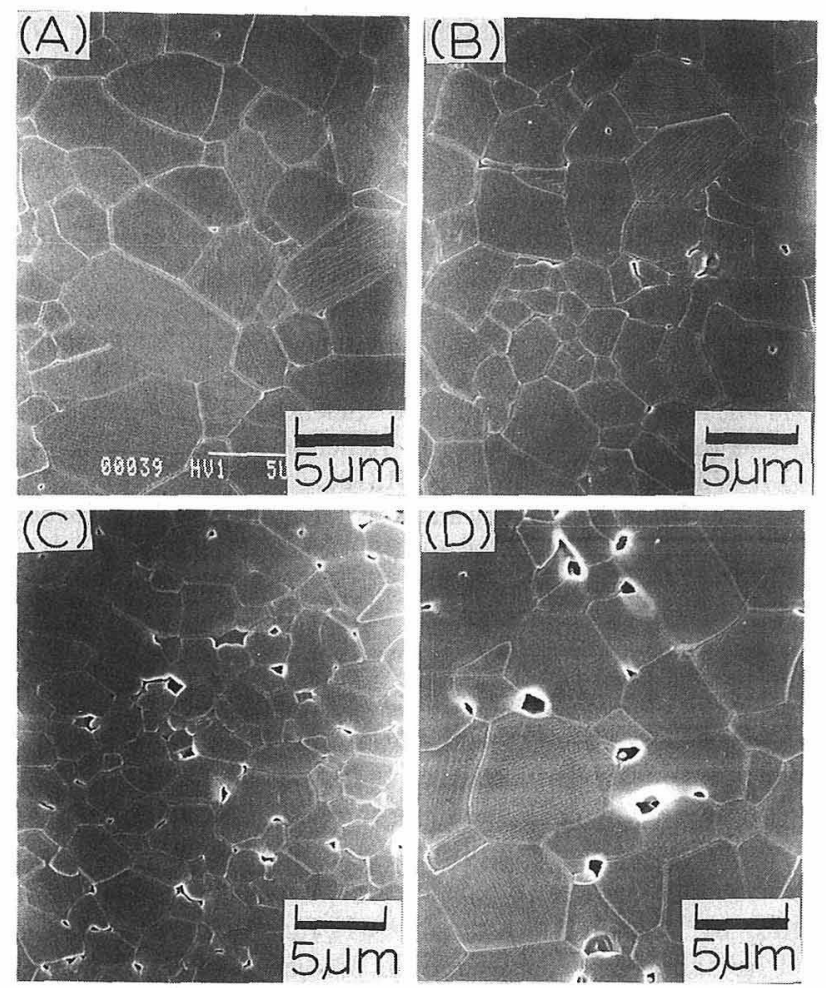

Fig. 14. Microstructures of alumina compacts sintered at $1600^{\circ} \mathrm{C}$ for $1 \mathrm{~h}$ and thermally etched at $1500^{\circ} \mathrm{C}$ for $1 \mathrm{~h}$. Samples were same as Fig. 10 and relative densities were $97.7 \%$ for sample A, $98.5 \%$ for sample B, $97.8 \%$ for sample C, and $97.7 \%$ for sample D.

tructures between samples $\mathrm{A}$ and $\mathrm{B}$ indicates that $\mathrm{PAN}$-addition in suspension stage was effective in achieveing a fine texture of a narrow grain size distribution. The microstructural comparison of samples $\mathrm{B}$ and $\mathrm{C}$ suggests that both the samples gave a similar average grain size, but more grain growth is needed in sample $\mathrm{C}$ to eliminate the closed pores distributed at grain boundaries. As shown in Fig. 12, little difference in densification behavior was observed in samples C and D. However, degree of grain growth was significant in sample D than sample C. This result reflects the feature of pore size distributions of green compacts. A wide pore size distribution (sample D) formed a small number of large pores at the grain boundaries of large grains, while a narrow pore size distribution (sample C) gave a texture with a large number of small closed pores distributed at the grain boundaries of small grains.

\section{Summary}

Effects of addition of polyacrylic ammonium (shorten as PAN) on colloidal processing of ceramics were investigated with aqueous suspensions of $\alpha$ alumina powder with an equivalent spherical diameter of $0.35 \mu \mathrm{m}$. The added PAN was completely adsorbed onto the alumina surface below a critical amount of $\sim 3.5 \times 10^{-6} \mathrm{~mol}$ carboxyl group per $\mathrm{m}^{2}$ of alumina surface at $\mathrm{pH} 9.0$. The zeta potential of alumina powder $(-24 \mathrm{mV}$ at $\mathrm{pH} 9.0)$ reached -40
$\mathrm{mV}$ with addition of the critical amount of negatively charged polymer, and free polymer above the critical amount didn't affect the zeta potential.

The viscosities of PAN-added alumina suspensions showed a first minimum at the critical amount of PAN, and increased with increasing free polymer content. Further addition of PAN caused the secondary minimum of viscosity as a function of PAN content. It was possible to prepare a highly concentrated fluid alumina suspension of $\approx 63 \mathrm{vol} \%$ solids by addition of the critical amount of PAN. However, it was difficult to increase the solids content above $53 \mathrm{vol} \%$ at $\mathrm{pH} 2.5$ in electrostatic stabilization with $\mathrm{HCl}$ solution.

The green densities of alumina compacts consolidated by filtration of electrostatically stabilized suspensions were independent of solids content in suspension stage, while the green densities for electrosteric stabilization with PAN showed a minimum at around solids content of $40 \mathrm{vol} \%$. The pore size distributions depended on both green densities and consolidation processes of powder (filtration or doctor blade method). A narrow pore size distribution was measured in a high-density green compact consolidated by filtration. The median size of pore in a green compact was small for electrostatic stabilization than electrosteric stabilization at a similar density, but PAN-addition was effective to produce a more continuous pore size distribution and a more uniform green structure.

Although the densification behavior was mainly dominated by green density, PAN-addition in suspension stage was effective in achieving a higher density and a more fine texture than electrostatic stabilization at the final stage of sintering. The densification of a high-density green compact proceeded with disappearance of closed pores which were formed at around $92-95 \%$ T. D. The low-density green compacts were densified without the significant formation of closed pores. The texture of sintered alumina was greatly affected by the pore size distribution of a green compact. A wide pore size distribution formed a small number of large pores at the grain boundaries of large grains, while a narrow pore size distribution gave a microstructure with many small closed pores located at the grain boundaries of small grains.

\section{References}

1) B. A. Bender, R. P. Ingel, W. J. McDonough and J. R. Spann, Adv. Ceram. Mater., 1, 137-44 (1986).

2) K. Nihara, Seramikkusu Ronbunshi (J. Ceram. Soc. Japan), 99, 974-82 (1991).

3) Y. Hirata and I. A. Aksay, "Ceramic Microstructures '86, Role of Interfaces, Materials Science Research, Vol. 21", Ed. by J. A. Pask and A. G. Evans, Plenum Press (1987) pp. 611-21.

4) Y. Hirata, S. Matsushita, S. Nakagama, Y. Ishihara and S. Hori, Seramikkusu Ronbunshi (J. Ceram. Soc. Japan), 97, 881-87 (1989).

5) Y. Hirata, I. A. Aksay, R. Kurita, S. Hori and H. Kaji, "Ceramic Transactions, Vol. 6, Mullite and Mullite Matrix Com- 
posites", Ed. by R. F. Davis, J. A. Pask and S. Sōmiya, The Am. Ceram. Soc., Inc. (1990) pp. 323-28.

6) Y. Hirata, I. Haraguchi and Y. Ishihara, Seramikkusu Ronbunshi (J. Ceram. Soc. Japan), 98, 951-56 (1990).

7) Y. Hirata, S. Matsushita, Y. Ishihara and H. Katsuki, J. Am. Ceram. Soc., 74, 2438-42 (1991).

8) Y. Hirata, K. Takeshima and Y. Ishihara, Proc. 1st Int. Symp. on the Science of Engineering Ceramics, Ed. by S. Kimura and K. Niihara, The Ceram. Soc. Japan (1991) pp. $321-26$.

9) Y. Hirata, Proc. Int. Symp. on Fine Ceramics, Arita '91, Saga Prefectural Government (1991) pp. 31-46.

10) Y. Hirata, K. Takeshima and Y. Ishihara, J. Ceram. Soc. Japan, 100, 353-61 (1992).

11) J. Cerasano, III, I. A. Aksay and A. Bleier, J. Am. Ceram. Soc., 71, 250-55 (1988).
12) J. Cerasano, III and I. A. Aksay, J. Am. Ceram. Soc., 71, 1062-67 (1988).

13) Y. Hirata, J. Kamikakimoto, A. Nishimoto and Y. Ishihara, J. Ceram. Soc. Japan, 100, 7-12 (1992).

14) Y. Hirata, S. Nakagama and Y. Ishihara, Seramikkusu Ronbunshi (J. Ceram. Soc. Japan), 98, 316-21 (1990).

15) D. J. Shaw, "Introduction to Colloid and Surface Chemistry", Butterworths (1980) pp. 208-11.

16) F. F. Lange, "Ceramic Transactions, Vol. 22, Ceramic Powder Science IV", Ed. by S. Hirano, G. L. Messing and H. Hausner, The Am. Ceram. Soc., Inc. (1991) pp. 185-201.

17) I. A. Aksay and R. Kikuchi, "Science of Ceramic Chemical Processing", Ed. by L. L. Hench and D. R. Ulrich, John Wiley \& Sons (1986) pp. 513-21.

18) Y. Hirata, I. A. Aksay and R. Kikuchi, Seramikkusu Ronbunshi (J. Ceram. Soc. Japan), 98, 126-35 (1990). 